\title{
Cáncer Ginecológico en el Hospital Universitario San Vicente de Paúl de Medellín $1970-1984$
}

\author{
DEPARTAMENTO DE OBSTETRICIA Y GINECOLOGIA \\ FACULTAD DE MEDICINA - UNIVERSIDAD DE ANTIOQUIA \\ Dr. Jaime Botero Uribe
}

Las cinco primeras causas de mortalidad en Colombia son: tumores malignos, otras enfermedades del corazón, enfermedades isquémicas del mismo, enfermedades cerebrovasculares y homicidios (1).

\section{FIGURA No. 1}

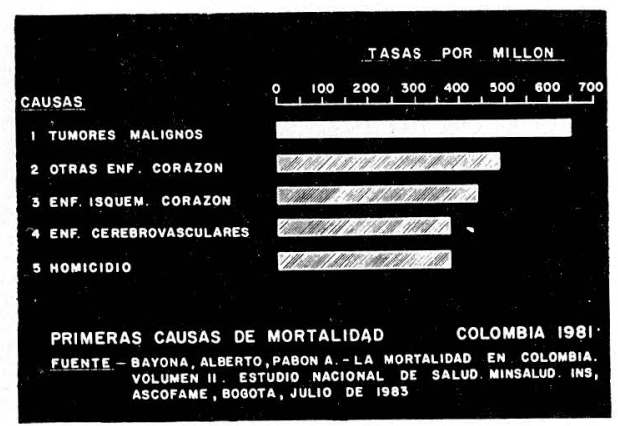

En el año de 1980 la incidencia de cáncer fue de $88 \times 100.000$ habitantes. En ese año ocurrieron 22.830 casos, de los cuales 14.980 , el $65 \%$, correspondieron a mujeres y la frecuencia conque en ellas ocurren las distintas localizaciones es la siguiente:

\begin{tabular}{lll}
\hline Aparato genital, & $48.9 \%$ \\
Mama, & $10.8 \%$ \\
Piel, & $14.7 \%$ \\
Aparato digestivo, & $10.7 \%$ \\
Boca, & 3 & $\%$ \\
\hline
\end{tabular}

El resto corresponde a localizaciones menos frecuentes (2).

La mortalidad por cáncer entre nosotros está alrededor de $5 \times 100.000$ habitantes. En el grupo de mujeres entre 15 y 44 años, el 14응 mueren de cáncer.

A partir de los 45 años, los tumores malignos ocasionan una de cada cinco muertes entre los 45 y los 59 años. Además de su alta incidencia, el cáncer ha venido aumentando en los últimos años, como lo demuestra el hecho de que en 1973 estaba en el tercer lugar y en 1977 pasó al segundo. El cáncer de mama muestra una curva ascendente desde 1960 y el de cervix no muestra signos de descenso (2). 
FIGURA No. 2

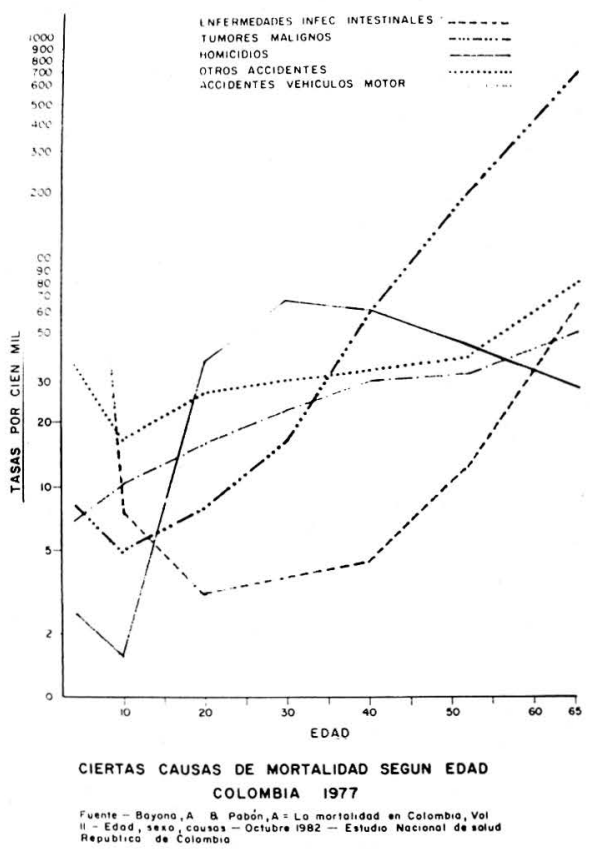

En los Departamentos de Antioquia y Caldas, similares desde el punto de vista etnográfico, la incidencia es aún más alta (2). El estudio de egresos hospitalarios en Antioquia muestra que en 1978 correspondieron en un 76.5 por 100.000 a cáncer, y en 1980 en un $117.2 \times 100.000$ (3). En estos departamentos, el cáncer ocupa el primer lugar entre las causas de muerte a partir del grupo de 35 a 44 años de edad (2).

Estas cifras sirven para colocarnos en la perspectiva apropiada que nos permita ver que el cáncer es una de nuestras prioridades de atención en salud, y debido al hecho de que el que se localiza en el aparato genital femenino es el más frecuente, se deduce fácilmente nuestra gran responsabilidad para estudiarlo en forma completa, para buscar mecanismos cada vez más efectivos de diagnosticarlos en forma temprana y oportuna y para señalar las principales medidas dirigidas a su prevención. La Federación Colombiana de Sociedades de Obstetricia y Ginecología, orientadora de la especialidad en el País, es la entidad más indicada para dar las pautas apropiadas y señalar los caminos que deben explorarse con el fin de conseguir esas metas.

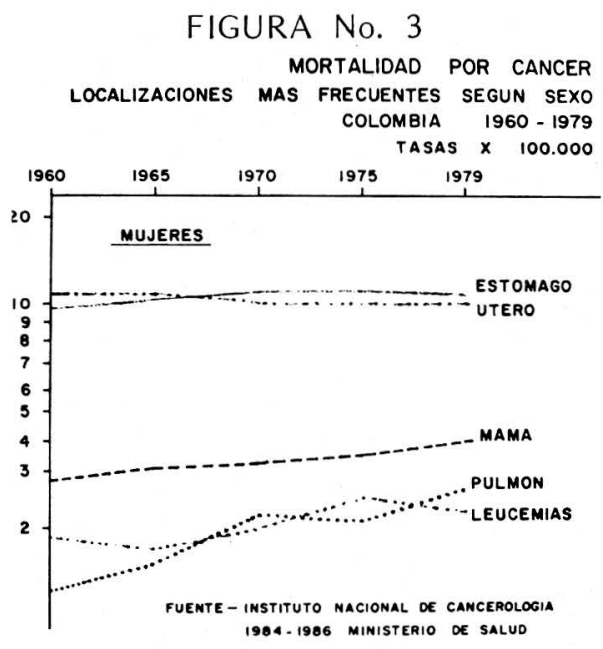

La Asociación Antioqueña de Obstetricia y Ginecología se ha ocupado en esta oportunidad de ver los resultados del tratamiento de los cánceres de vulva, de cuello uterino estadios la y $b$, de endometrio y de ovario, que han sido atendidos en el Hospital Universitario San Vicente de Paúl, aprovechando el registro que desde el año de 1970 se inició bajo la dirección del Dr. Jaime Uribe Duque y que en los últimos años ha sido compilado mediante el uso de un microcomputador Apple lle, utilizando el programa Applework.

Los resultados obtenidos hasta ahora queremos compartirlos con ustedes, para 
oír sus críticas, comentarios y sugerencias, con el fin de iniciar una nueva etapa, aprovechando la experiencia que hemos adquirido hasta el momento, Queremos destacar el hecho de que el grupo que ha manejado estas pacientes durante los últimos 15 años ha sido prácticamente el mismo, e incluye además al Profesor René Díaz Correa hasta junio de 1983, cuando se retiró de la Cátedra después de cumplir durante 38 años una meritoria labor docente. Sea este el momento de rendirle un justo homenaje de agradecimiento en nombre de todos sus compañeros del grupo de Oncología. Su constancia en el trabajo, asiduidad y responsabilidad mi-

\section{REFERENCIAS}

1. BAYONA, A. y PABON, A.: La mortalidad en Colombia. Vol. II. Estudio Nacional de Salud. Minsalud, INS, Ascofame, Bogotá, julio 1983.

2. BAYONA, A. y PABON, A.: La mortalidad en Colombia. Vol. II. Edad, sexo y causas. Estudio Nacional de Salud. República de Colombia. Bogotá. Instituto Nacional de Salud, 1982. nuciosa en la labor científica, exquisito respeto por el paciente y por el colega y discreción en la presentación de sus puntos de vista y opiniones, lo han hecho el verdadero prototipo del profesional, digno sucesor de quienes fueron sus mentores y maestros.

Finalmente, la Fundación Pedro Nel Cardona viene contribuyendo al funcionamiento de este programa desde noviembre de 1975, apoyando principalmente la organización de las labores de seguimiento de pacientes y el estudio colposcópico de las lesiones premalignas del cuello uterino.
3. Instituto Nacional de Cancerología. Programa Nacional de Cáncer. Período 1984-1986. República de Colombia. Ministerio de Salud. Bogotá, D.E. Mimeografiado.

4. DUQUE, A. y CARVAJAL, P.: Egresos por Cáncer en el Depto. de Antioquia. 1978-1980. Boletín Epidemiológico de Antioquia. Año 7. No. 3. Jul., Agos. Sept., 1982. Págs. 84-88. 